Check for updates

Cite this: Phys. Chem. Chem. Phys., 2019, 21, 22248

Received 16th August 2019,

Accepted 14th September 2019

DOI: $10.1039 / c 9 c p 04554 f$

rsc.li/pccp

\section{From benzene to naphthalene: direct measurement of reactions and intermediates of phenyl radicals and acetylene $\uparrow$}

\author{
Te-Chun Chu, (D) Zachary J. Buras, (D) Mica C. Smith, (D) Awele B. Uwagwu and \\ William H. Green (DD*
}

\begin{abstract}
Hydrogen-abstraction $-\mathrm{C}_{2} \mathrm{H}_{2}$-addition (HACA) is one of the most important pathways leading to the formation of naphthalene, the simplest two-ring polycyclic aromatic hydrocarbon (PAH). The major reaction channels for naphthalene formation have previously been calculated by Mebel et al., but few experiments exist to validate the theoretical predictions. In this work, time-resolved molecular beam mass spectrometry (MBMS) was used to investigate the time-dependent product formation in the reaction of a phenyl radical with $\mathrm{C}_{2} \mathrm{H}_{2}$ for the first time, at temperatures of 600 and $700 \mathrm{~K}$ and pressures of 10 and 50 Torr. A pressure-dependent model was developed with rate parameters derived from Mebel et al.'s calculations and from newly calculated pathways on the $\mathrm{C}_{8} \mathrm{H}_{7}$ PES at the G3(MP2,CC)//B3LYP/6-311G** level of theory. The model prediction is consistent with the MBMS product profiles at a mass-to-charge ratio $(\mathrm{m} / \mathrm{z})$ of 102 (corresponding to the $\mathrm{H}$-loss product from $\mathrm{C}_{8} \mathrm{H}_{7}$, phenylacetylene), 103 (the initial $\mathrm{C}_{8} \mathrm{H}_{7}$ adduct and its isomers plus the ${ }^{13} \mathrm{C}$ isotopologue of phenylacetylene), 128 (naphthalene), and $129\left(\mathrm{C}_{10} \mathrm{H}_{9}\right.$ isomers plus the ${ }^{13} \mathrm{C}$ isotopologue of naphthalene). An additional $\mathrm{C}_{8} \mathrm{H}_{7}$ isomer, bicyclo[4.2.0]octa-1,3,5-trien-7-yl, not considered by Mebel et al.'s calculations, contributes significantly to the signal at $m / z 103$ due to its stable energy and low reactivity. At high $\mathrm{C}_{2} \mathrm{H}_{2}$ concentrations, bimolecular reactions dominated the observed chemistry, and the $\mathrm{m} / \mathrm{z} 128$ and $\mathrm{m} / \mathrm{z} 102$ MBMS signal ratio was measured to directly determine the product branching ratio. At $600 \mathrm{~K}$ and $10 \mathrm{Torr}$, branching to the $\mathrm{H}$-loss product (phenylacetylene) on the $\mathrm{C}_{8} \mathrm{H}_{7}$ PES accounted for $7.9 \%$ of phenyl radical consumption, increasing to $15.9 \%$ at $700 \mathrm{~K}$ and 10 Torr. At 50 Torr, the branching was measured to be $2.8 \%$ at $600 \mathrm{~K}$ and $6.2 \%$ at $700 \mathrm{~K}$. Adduct stabilization is favored at higher pressure and lower temperature, which hinders the formation of the $\mathrm{H}$-loss product. The pressuredependent model predicted the observed branching ratios within the experimental uncertainty, indicating that the rate parameters reported here can be used in combustion mechanisms to provide insights into phenyl HACA reactions and $\mathrm{PAH}$ formation.
\end{abstract}

\section{Introduction}

Polycyclic aromatic hydrocarbons (PAHs) have attracted wide attention in combustion as precursors of soot,${ }^{1-5}$ and their build-up process from small molecules has a significant impact on process efficiency and the desired product selectivity. ${ }^{6-8} \mathrm{~A}$ number of kinetic models have been proposed to understand the formation of naphthalene, one of the simplest two-ring PAHs, most notably the hydrogen-abstraction- $\mathrm{C}_{2} \mathrm{H}_{2}$-addition (HACA) mechanism starting from benzene and a phenyl radical $\left(\mathrm{C}_{6} \mathrm{H}_{5}\right)$ due to its accessible entrance barrier and significant exothermicity. ${ }^{1,3,9}$ The potential energy surface (PES) of $\mathrm{C}_{6} \mathrm{H}_{5}+$ acetylene $\left(\mathrm{C}_{2} \mathrm{H}_{2}\right)$ was reported by Richter et al. at the B3LYP/cc-PVDZ level of

Massachusetts Institute of Technology, 77 Massachusetts Avenue, Cambridge, MA 02139, USA. E-mail: whgreen@mit.edu

$\dagger$ Electronic supplementary information (ESI) available. See DOI: 10.1039/c9cp04554f theory with pressure-dependent rate constant calculations. ${ }^{10}$ Tokmakov et al. further investigated the $\mathrm{C}_{6} \mathrm{H}_{5}+\mathrm{C}_{2} \mathrm{H}_{2}$ reaction using the G2M method and applied Rice-Ramsperger-KasselMarcus (RRKM) theory to predict the kinetics and product branching ratios. ${ }^{11}$ To investigate the chemistry beyond the $\mathrm{C}_{8} \mathrm{H}_{7}$ PES, Kislov et al. used the G3(MP2,CC) level of theory to explore the reactions involving a second acetylene addition, which include $\mathrm{C}_{8} \mathrm{H}_{5}, \mathrm{C}_{10} \mathrm{H}_{7}$, and $\mathrm{C}_{10} \mathrm{H}_{9}$ PESs, as well as other important reactions in HACA chemistry. ${ }^{12}$ With the kinetics evaluated from those calculations, the Diels-Alder mechanism was found to be much slower than the HACA mechanism at high combustion temperatures. More recent calculations reported by Mebel et al. improved Kislov et al.'s calculations ${ }^{12}$ by performing RRHO-based variational transition state theory (VTST) calculations for low-barrier reactions and variable reaction coordinate-transition state theory (VRC-TST) ${ }^{13}$ for barrierless $\mathrm{H}$-elimination reactions on the $\mathrm{C}_{10} \mathrm{H}_{7}$ PES. ${ }^{14}$ Branching ratios 
in a wide range of temperatures and pressures were evaluated, and naphthalene was predicted to be the dominant product at temperatures of up to $2500 \mathrm{~K}$.

Several experimental kinetics studies of $\mathrm{C}_{6} \mathrm{H}_{5}$ HACA reactions have also been performed. Fahr and Stein conducted pyrolysis experiments in a flow reactor to measure the kinetics of phenylacetylene $+\mathrm{H}$ formation at $1000-1330 \mathrm{~K} \cdot{ }^{15} \mathrm{Yu}$ et al. used cavity ringdown spectroscopy to measure the total $\mathrm{C}_{6} \mathrm{H}_{5}+$ acetylene rate constant at 297-523 K, and by assuming a constant $\mathrm{C}_{6} \mathrm{H}_{5}$ recombination rate, they correlated their rates measured at relatively low temperatures with those measured in Fahr et al.'s experiments. ${ }^{15-17}$ Using a reflectron time of flight mass spectrometer, Parker et al. directly observed the formation of phenylacetylene and naphthalene in the phenyl + acetylene reaction. ${ }^{18}$ Subsequent work by Yang et al. found further evidence of the styrenyl and ortho-vinylphenyl radicals, which supported previous theoretical work. ${ }^{19}$ However, the time-dependent products and the product branching ratio have not been directly measured previously.

In this work, we directly measured the time dependent formation of products in the $\mathrm{C}_{6} \mathrm{H}_{5}+\mathrm{C}_{2} \mathrm{H}_{2}$ HACA reaction using molecular beam mass spectrometry (MBMS) under a range of $T$ and $P$ conditions (600-700 K and 10-50 Torr). A pressuredependent model was developed using Mebel et al.'s ab initio calculations ${ }^{14}$ and additional pathways on the $\mathrm{C}_{6} \mathrm{H}_{5}+\mathrm{C}_{2} \mathrm{H}_{2}$ PES calculated here, and compared with our experimental data to assess the validity of the proposed reaction channels for accurately predicting the formation of naphthalene via the HACA mechanism.

\section{Experimental}

The experimental apparatus used in this work has been described previously. ${ }^{20-22}$ Time-resolved molecular beam mass spectrometry (MBMS) was used to measure product signals at pressures of 10 and 50 Torr and temperatures of 600 and $700 \mathrm{~K}$. Experiments were performed in a custom quartz flow reactor $(1.6 \mathrm{~cm}$ inner diameter in the reaction region) in a high vacuum chamber equipped with a reflectron time-of-flight mass spectrometer (Kore TOF-MS). Gases were well-mixed before flowing into the reactor and were pumped using a Roots blower (Leybold). The pressure in the reactor was held constant at 10 or 50 Torr by throttling a butterfly valve leading to the pump at the reactor outlet. The reactor was wrapped with nichrome ribbon wire for heating up the gas to the desired temperatures, and two thermocouples were located inside the reactor to control the temperature. Prior to the experiments, axial temperature profiles with $2.5 \mathrm{~cm}$ resolution along the length of the reactor were measured to obtain the real temperatures of the gas mixture used for kinetic modeling.

A collimated pulsed $266 \mathrm{~nm}$ laser beam (fourth harmonic frequency of an Nd:YAG laser) with $1 \mathrm{~Hz}$ repetition rate was focused coaxially into the reactor to photolyze the radical precursor. The total gas flow rate was adjusted to maintain one flash per refresh condition. Additional experiments with higher $\mathrm{C}_{2} \mathrm{H}_{2}$ concentration were performed under each set of temperature and pressure conditions. The gas mixture was sampled through a pinhole in the reactor center and formed a molecular beam intersecting with a focused $118 \mathrm{~nm}(10.5 \mathrm{eV})$ photoionization laser beam (ninth harmonic frequency of an Nd:YAG laser), which formed cations measured by MBMS. Time-of-flight mass spectra were measured at reaction times of up to $8 \mathrm{~ms}$ after the photolysis pulse in order to observe products from both the first and the second $\mathrm{C}_{2} \mathrm{H}_{2}$ addition. Peaks on the mass spectra at different mass-to-charge ratios $(\mathrm{m} / \mathrm{z})$ were integrated and compared with model predictions. Before the laser beam entered the reactor, an adjustable iris was placed in its path to control the size of the laser beam. The laser diameter was clipped from $1.8 \mathrm{~cm}$ to $1.5 \mathrm{~cm}$, slightly smaller than the reactor inner diameter, which gives two main advantages: (1) clipping the edges of the beam can decrease inhomogeneities in the radical concentration produced by the laser beam. (2) No direct contact was made between the reactor inner wall and the laser beam, reducing undesired wall reactions which apparently promote the fast hydrogenation of the phenyl radical to benzene, observed in MBMS experiments when the laser beam size was not optimized. ${ }^{21}$ Nitrosobenzene $\left(\mathrm{C}_{6} \mathrm{H}_{5} \mathrm{NO}\right.$; Sigma-Aldrich, 98\%) was used as the photolytic precursor of the phenyl radical $\left(\mathrm{C}_{6} \mathrm{H}_{5}\right){ }^{16,17}$ To remove oxygen and impurities, several freeze-pump-thaw cycles were performed on $\mathrm{C}_{6} \mathrm{H}_{5} \mathrm{NO}{ }^{21}$ Helium (He) was the carrier gas and bath gas for all the experiments with UHP grade purity ( $\geq 99.999 \%)$ obtained from Airgas; acetylene $\left(\mathrm{C}_{2} \mathrm{H}_{2}\right)$ with $\geq 99.5 \%$ purity was used (CP grade) and was also purchased from Airgas; and acetone in the acetylene was removed using a cartridge activated charcoal gas purifier (SGD80003) obtained from Airgas.

\section{Theoretical}

The HACA routes of $\mathrm{C}_{6} \mathrm{H}_{5}$ were previously explored by Mebel et al. at the G3(MP2,CC)//B3LYP/6-311G ${ }^{* *}$ level of theory ${ }^{12}$ including $\mathrm{C}_{8} \mathrm{H}_{7}, \mathrm{C}_{10} \mathrm{H}_{7}$, and $\mathrm{C}_{10} \mathrm{H}_{9}$ potential energy surfaces (PESs) and other reactions such as $\mathrm{H}$-abstraction, radical recombination, or radical disproportionation. ${ }^{12,14}$ In this work, two additional $\mathrm{C}_{8} \mathrm{H}_{7}$ isomers (bicyclo[4.2.0]octa-2,4,7-trien-1-yl, $\mathrm{C}_{8} \mathrm{H}_{7}-3$, in Fig. 1 and bicyclo[4.2.0]octa-1,3,5-trien-7-yl, $\mathrm{C}_{8} \mathrm{H}_{7}-4$, in Fig. 1) and one $\mathrm{C}_{8} \mathrm{H}_{6}$ (benzocyclobutadiene, $\mathrm{C}_{8} \mathrm{H}_{6}-2$ in Fig. 1) $+\mathrm{H}$ product along with four transition states are included in the updated $\mathrm{C}_{8} \mathrm{H}_{7}$ PES, shown in Fig. 1. These species were reported by Richter et al. ${ }^{10}$ and Tokmakov and $\operatorname{Lin}^{11}$ in previous theoretical literature; the geometries were optimized and frequencies were calculated at the B3LYP/6-311G** level of theory using Richter et al.' ${ }^{10}$ geometry as the initial guess. The only exception is the transition state between $\mathrm{C}_{8} \mathrm{H}_{7}-4$ and $\mathrm{C}_{8} \mathrm{H}_{6}-2+\mathrm{H}$, which was optimized at the M062X/cc-pVTZ level of theory, because the B3LYP/6-311G** method could not find a correct converged geometry. Its frequencies were later calculated at the B3LYP/ 6-311G** level to keep it consistent with other species on the $\mathrm{C}_{8} \mathrm{H}_{7}$ PES. The energies of the stationary points and transition states were calculated using the same method as Mebel et al., ${ }^{14}$ G3(MP2,CC)//B3LYP/6-311G**. All the calculations were performed in Gaussian $16,{ }^{23}$ except for the $\operatorname{rCCSD}(\mathrm{T})$ energy used in the G3(MP2,CC) method which was obtained from Molpro 2015. ${ }^{24-34}$ Molecular parameters for the newly calculated 


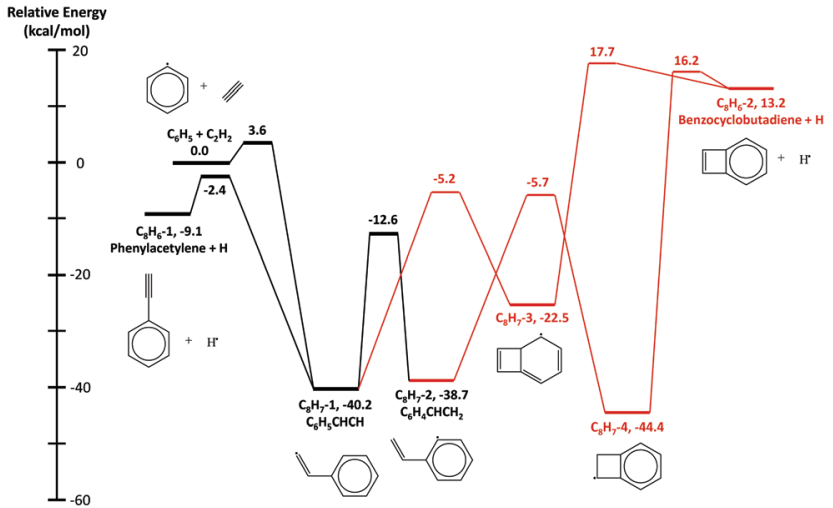

Fig. 1 Potential energy surface of the G3(MP2,CC) stationary point energies for the $\mathrm{C}_{6} \mathrm{H}_{5}+\mathrm{C}_{2} \mathrm{H}_{2}$ reaction. Black species and pathways were calculated by Mebel et al. Newly added species and pathways are marked in red.

stationary points are reported in the ESI. $\dagger$ For the rest of the species on the $\mathrm{C}_{8} \mathrm{H}_{7}, \mathrm{C}_{10} \mathrm{H}_{7}$ and $\mathrm{C}_{10} \mathrm{H}_{9}$ PESs, ab initio data were directly taken from the work of Mebel et al. ${ }^{14}$

Arkane, ${ }^{35}$ a package included in the open-source software Reaction Mechanism Generator (RMG), ${ }^{36}$ was used to calculate phenomenological pressure-dependent rate coefficients $k(T, P)$. The collisional energy-transfer parameter, $\left\langle\Delta E_{\text {down }}\right\rangle=\alpha(T)=$ $424 \times(T / 300 \mathrm{~K})^{0.62} \mathrm{~cm}^{-1}$, was taken from the work of Mebel et $a l .{ }^{37}$ for argon bath gas, and scaled down for helium bath gas using Jasper et al.'s method. ${ }^{38}$ While the theoretical rate coefficients reported by Mebel et al. ${ }^{14}$ were calculated using the direct diagonalization method to solve the master equation, ${ }^{39,40}$ the present work used the modified strong collision approximation to calculate $k(T, P)$ from pressure-dependent networks incorporating the additional pathways discussed above. cis/trans isomers with interconversion barriers $<4 \mathrm{kcal} \mathrm{mol}^{-1}$ are treated as lumped single species in our rate calculations. Lennard-Jones parameters for the different PESs were estimated from the reported transport properties of PAHs by Wang et al. ${ }^{41}$ Thermochemical properties for important species were obtained from the Narayanaswamy library in the RMG database, which focuses on aromatics formation and considers accurate experimental data along with G3MP2//B3 calculations. ${ }^{8}$ For other species not in the Narayanaswamy library, RMG was used to estimate their thermochemical properties with the group additivity method, which has recently been improved and extended by similarity matching and bicyclic decomposition for predicting fused cyclics. ${ }^{42}$ The abovementioned $k(T, P)$ and thermochemical properties were used to construct a pressure-dependent kinetic mechanism for $\mathrm{C}_{6} \mathrm{H}_{5}+$ $\mathrm{C}_{2} \mathrm{H}_{2}$. In addition to the main HACA routes, the mechanism includes side reactions that are important under our experimental conditions, such as addition of $\mathrm{H}$ atoms formed in HACA reactions to $\mathrm{C}_{2} \mathrm{H}_{2}$ forming vinyl radicals. The mechanism is attached in the $\mathrm{ESI}^{\dagger}$ in Chemkin format with the rate parameters and the species thermochemistry.

The detailed chemical mechanism for various $\mathrm{C}_{6} \mathrm{H}_{5}$ HACA pathways was used to simulate the time-dependent species concentrations under the conditions of the MBMS experiments to compare the theoretical calculations with the measured product signals. A similar approach was used by Buras et al. ${ }^{21}$ for experiments performed in the same apparatus. To account for the transport effects in molecular beam sampling and the reactor, a constant $0.2 \mathrm{~ms}$ time delay with a simple model with a first-order rate constant ( $\left.k_{\text {sampling }}\right)$ was utilized, which was adapted from Baeza-Romero et al. ${ }^{43}$ A previous work ${ }^{21}$ used the rise time of the I atom signal to estimate the sampling rate, which is not available in the present work, since we did not use the iodide. Here nitric oxide (NO), cogenerated with $\mathrm{C}_{6} \mathrm{H}_{5}$ through photolysis, was chosen to fit $k_{\text {sampling, because it is }}$ barely affected by the $\mathrm{C}_{6} \mathrm{H}_{5}+\mathrm{C}_{2} \mathrm{H}_{2}$ reactions. An example of the NO time series measured by MBMS experiments is given in the ESI $\dagger$ to compare with the model prediction with $k_{\text {sampling. }}$. The fitted $k_{\text {sampling }}$ only affects the time dependence of the absolute predicted signals, but has no effect on the relative abundance of species at any given time point. For most experiments, the fitted value of $k_{\text {sampling }}$ was $1600-2000 \mathrm{~s}^{-1}$, whereas a smaller value $\left(1200 \mathrm{~s}^{-1}\right)$ was found for one experiment, possibly due to a shifted laser alignment. To further convert the species concentration into signals compared to the observed signals in the experiments, the predicted species concentration $\left(C_{\mathrm{i}}\right)$ after sampling was weighted by the photoionization cross section (PICS) for each species at $10.5 \mathrm{eV}(118.2 \mathrm{~nm}): \sigma_{\mathrm{NO}}=3.1 \mathrm{Mb},{ }^{44}$ $\sigma_{\text {phenylacetylene }}=63.0 \mathrm{Mb}^{45}(10 \%$ uncertainty $), \sigma_{\mathrm{C}_{8} \mathrm{H}_{7} \text { radical }}=8 \mathrm{Mb}$ (a factor of two uncertainty), $\sigma_{\text {naphthalene }}=51.4 \mathrm{Mb}^{18,46,47}$ (50\% uncertainty), and $\sigma_{\mathrm{C}_{10} \mathrm{H}_{9}}$ radical $=8 \mathrm{Mb}$ (a factor of two uncertainty). Lower PICS values were estimated for the radical species relative to the close-shell species, because of the correspondingly lower occupancy of the HOMO from which the electron is ejected. ${ }^{48}$ However, aromatic resonance stabilized radicals (RSRs) commonly have PICS similar to the corresponding closed-shell structure, i.e. the benzyl radical $\left(25.5 \mathrm{Mb}^{49}\right)$ compared to toluene $\left(32.0 \mathrm{Mb}^{45}\right)$. Since both $\mathrm{C}_{8} \mathrm{H}_{7}-3$ and $\mathrm{C}_{8} \mathrm{H}_{7}-4$ in the $\mathrm{C}_{8} \mathrm{H}_{7}$ PES are RSRs, their PICSs are estimated to be $40 \mathrm{Mb}$ (a factor of two uncertainty), similar to their closed-shell analogues, benzocyclobutane, with >50 Mb PICS at $10.5 \mathrm{eV}$ ionization energy estimated by Li et al. ${ }^{46}$ Due to the difference of PICS between some isomers, the MBMS measured signals cannot be converted to the lumped concentration of isomers; thus, the signals are compared instead of the species concentration in this work. The impact of ${ }^{13} \mathrm{C}$ isotopes was assumed to contribute $1.1 \%$ per carbon atom for each of the products, and the same PICS was assumed for each set of isotopomers. Finally, a scaling constant $C_{\mathrm{i}}$ obtained from the internal calibration mixture for each experimental condition was multiplied with the PICS to obtain the time-dependent predicted product signals. Steps of the described modeling approach are depicted in the ESI. $\dagger$ For the rate of production (ROP) analysis, Chemical Workbench ${ }^{50}$ was used to evaluate the reactant consumption under MBMS experimental conditions.

\section{Results \& discussion}

\subsection{Hydrogen-abstraction- $\mathrm{C}_{2} \mathrm{H}_{2}$-addition (HACA) routes of the phenyl radical}

In the HACA mechanism for the reaction of the phenyl radical with $\mathrm{C}_{2} \mathrm{H}_{2}$, three pathways have been identified leading to 


\section{Frenklach route}

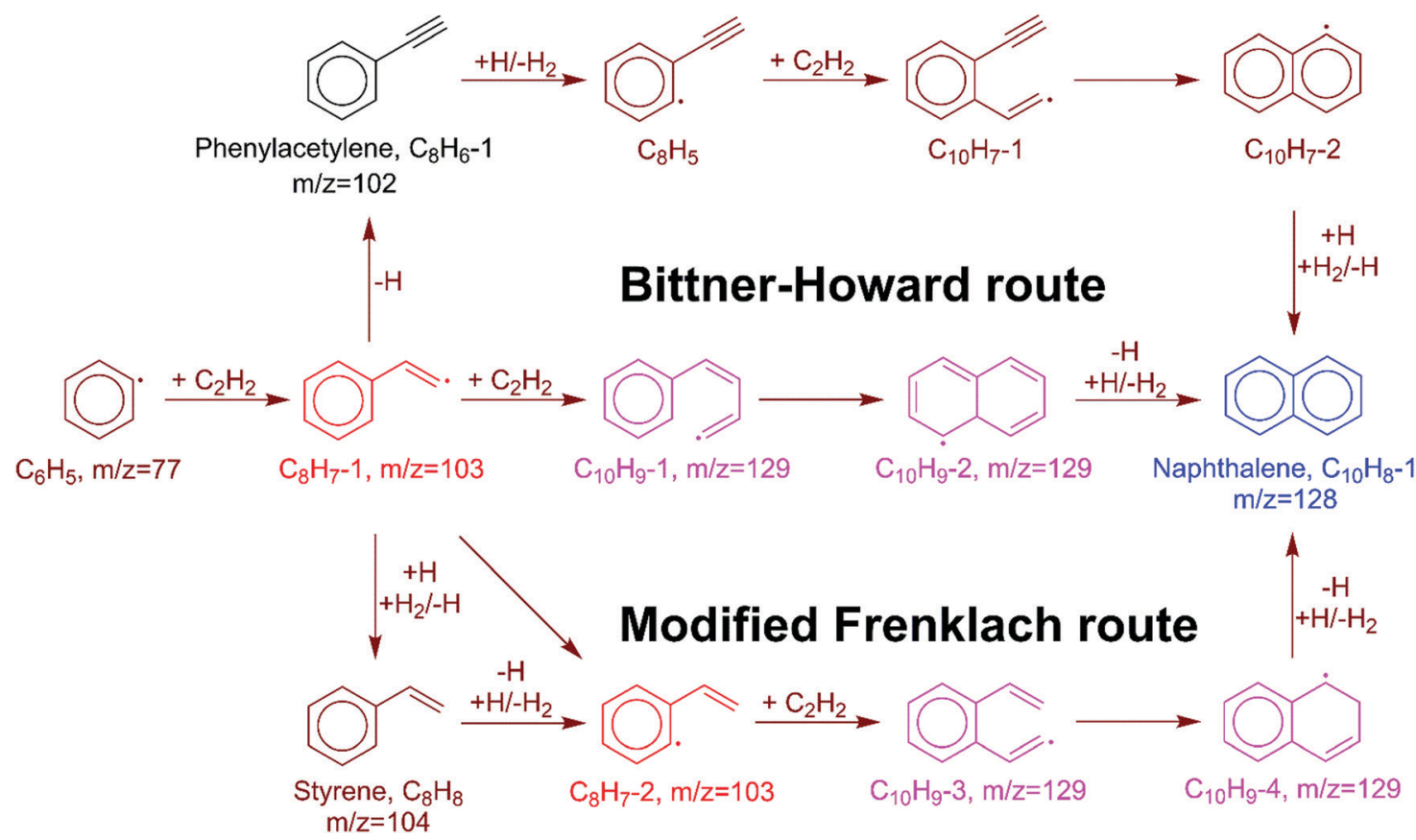

Fig. 2 HACA reactions of the phenyl radical including the Frenklach, Bittner-Howard, and modified Frenklach routes. The main products observed in the MBMS experiments are indicated in black (phenylacetylene, $\mathrm{m} / \mathrm{z}=102)$, red $\left(\mathrm{C}_{8} \mathrm{H}_{7}\right.$ isomers $\left.\mathrm{m} / \mathrm{z}=103\right)$, blue (naphthalene, $\left.\mathrm{m} / \mathrm{z}=128\right)$, and pink $\left(\mathrm{C}_{10} \mathrm{H}_{9}\right.$ isomers, $m / z=129$ ).

naphthalene formation: the Frenklach, ${ }^{3,9,51}$ Bittner-Howard, ${ }^{52}$ and modified Frenklach ${ }^{53,54}$ routes. Reactions involved in each route are depicted in Fig. 2. In our previous study on methanerich combustion at high temperature $(>1400 \mathrm{~K})$, the Frenklach route was the most important pathway of naphthalene formation, ${ }^{6}$ which involves external $\mathrm{H}$ abstraction from phenylacetylene $\left(\mathrm{C}_{8} \mathrm{H}_{6}\right)$ forming a $\mathrm{C}_{8} \mathrm{H}_{5}$ radical before the second $\mathrm{C}_{2} \mathrm{H}_{2}$ addition. However, this route is not expected to be significant under the experimental conditions (600-700 K, 10-50 Torr) of this work where $\mathrm{H}$ atoms are generated from $\mathrm{H}$-loss reactions. Due to high $\mathrm{C}_{2} \mathrm{H}_{2}$ concentration in our MBMS experiments, $\mathrm{H}$ atoms are mostly consumed by $\mathrm{C}_{2} \mathrm{H}_{2}$ instead of reacting with phenylacetylene; therefore, no clear time-dependence of the $m / z=127$ signal corresponding to $\mathrm{C}_{10} \mathrm{H}_{7}$ isomers was observed, which supports this hypothesis.

In the Bittner-Howard route, the initial adduct of $\mathrm{C}_{6} \mathrm{H}_{5}+$ $\mathrm{C}_{2} \mathrm{H}_{2}, \mathrm{C}_{8} \mathrm{H}_{7}-1$, directly reacts with the second $\mathrm{C}_{2} \mathrm{H}_{2}$ to form the $\mathrm{C}_{10} \mathrm{H}_{9}-1$ radical, followed by isomerization and $\beta$-scission to the final product, naphthalene. In the modified Frenklach route, $\mathrm{C}_{8} \mathrm{H}_{7}-2$ can be generated via the direct well-skipping reaction of $\mathrm{C}_{6} \mathrm{H}_{5}+\mathrm{C}_{2} \mathrm{H}_{2}$, isomerization of $\mathrm{C}_{8} \mathrm{H}_{7}-1$, or an $\mathrm{H}$-assisted pathway involving the formation of styrene. The existence of styrene in this route suggests that we may expect observation of a signal at $m / z=104$ in the MBMS experiments. Naphthalene is formed in a similar manner to the Bittner-Howard route by the reaction of $\mathrm{C}_{8} \mathrm{H}_{7}-2$ with $\mathrm{C}_{2} \mathrm{H}_{2}$, isomerization, and $\beta$-scission. Both the BittnerHoward route and the modified Frenklach route involve reactions on the $\mathrm{C}_{10} \mathrm{H}_{9}$ PES. Under low pressure or high temperature conditions, well-skipping reactions become important even for fairly large molecules; ${ }^{55}$ therefore, the $\mathrm{C}_{8} \mathrm{H}_{7}-1+\mathrm{C}_{2} \mathrm{H}_{2}$ and $\mathrm{C}_{8} \mathrm{H}_{7}-2+\mathrm{C}_{2} \mathrm{H}_{2}$ reactions can produce naphthalene $+\mathrm{H}$ without stabilization of $\mathrm{C}_{10} \mathrm{H}_{9}$ isomers. All of these reactions have been included in the pressure-dependent model developed in this work.

\subsection{Products measured by MBMS experiments}

Time-resolved mass-spectra after background subtraction measured at $700 \mathrm{~K}$ and 10 Torr are shown in Fig. 3. A negative signal appears at $m / z 107\left(\mathrm{C}_{6} \mathrm{H}_{5} \mathrm{NO}\right)$ after $t=0$ due to the photolysis of the chemical precursor, and $m / z=30(\mathrm{NO})$ and $m / z=77\left(\mathrm{C}_{6} \mathrm{H}_{5}\right)$ peaks appear as the photolysis products are co-generated. The signal at $m / z=30$ slowly increases to its maximum value due to the molecular beam sampling effect, and it remains nearly constant at longer reaction times, indicating that NO is not reactive. The signal of the phenyl radical, on the other hand, decreases rapidly due to its fast reaction with $\mathrm{C}_{2} \mathrm{H}_{2}$. The products of the reaction between $\mathrm{C}_{6} \mathrm{H}_{5}$ and the first $\mathrm{C}_{2} \mathrm{H}_{2}$ appear at $\mathrm{m} / \mathrm{z}=102$ (H-loss product, phenylacetylene), 103 (the initial adduct $\mathrm{C}_{8} \mathrm{H}_{7}-1$ and its isomers plus the ${ }^{13} \mathrm{C}$ isotopologue of phenylacetylene), and 104 (styrene, the side product in the modified Frenklach route). As the $\mathrm{C}_{8} \mathrm{H}_{7}$ isomers further react with a second $\mathrm{C}_{2} \mathrm{H}_{2}$, signals at $\mathrm{m} / \mathrm{z}=128$ (naphthalene) and $129\left(\mathrm{C}_{10} \mathrm{H}_{9}\right.$ isomers plus the ${ }^{13} \mathrm{C}$ isotopologue of naphthalene) are observed in the mass spectra. The signal at $m / z=154$ corresponds to biphenyl produced from phenyl radical recombination, which is less significant at higher temperature.

When $\mathrm{H}$ atoms are eliminated in $\beta$-scission reactions, they rapidly react with the high concentration $\mathrm{C}_{2} \mathrm{H}_{2}$ in the reactor to generate $\mathrm{C}_{2} \mathrm{H}_{3}$ (vinyl radical, $m / z=27$ ). Similar to the HACA 
(a)

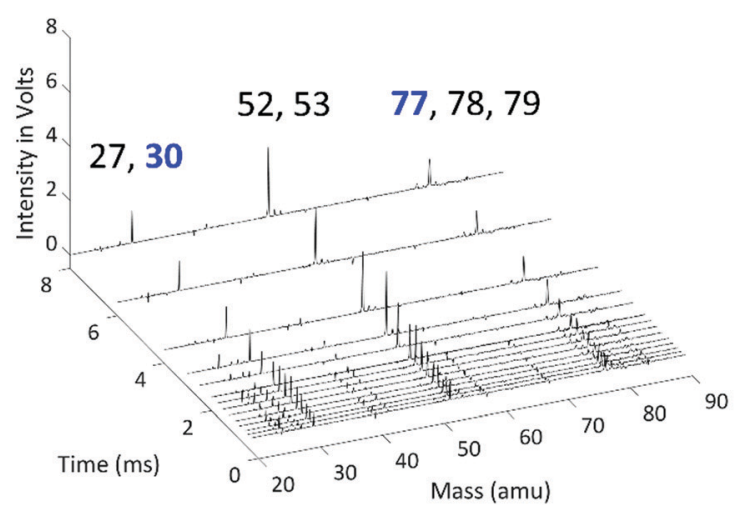

(b)

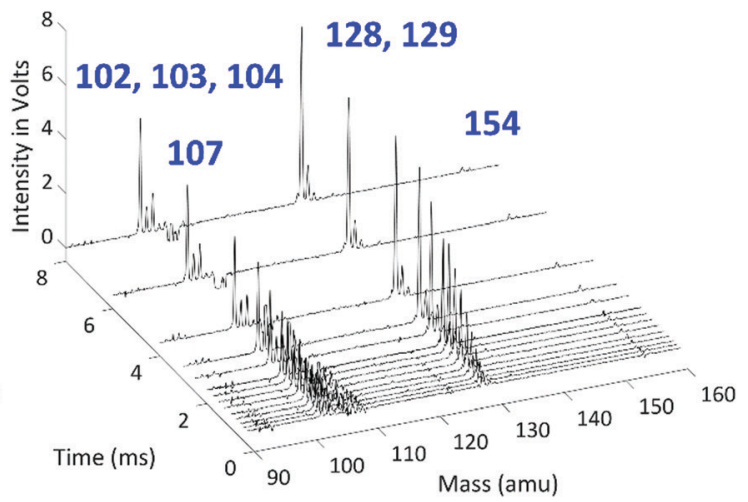

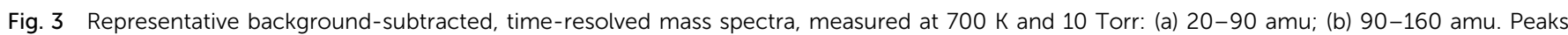

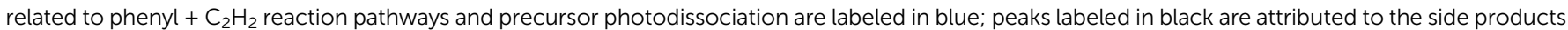
of the vinyl $+\mathrm{C}_{2} \mathrm{H}_{2}$ reaction.

reactions of the phenyl radical to form naphthalene, a vinyl radical can react with two $\mathrm{C}_{2} \mathrm{H}_{2}$ molecules to form benzene. The observed signals at $m / z=52$ (vinylacetylene), $m / z=53\left(\mathrm{C}_{4} \mathrm{H}_{7}\right.$ isomers plus the ${ }^{13} \mathrm{C}$ isotopologue of $\left.\mathrm{m} / \mathrm{z}=52\right), \mathrm{m} / \mathrm{z}=$ 78 (benzene), and $m / z=79\left(\mathrm{C}_{6} \mathrm{H}_{7}\right.$ isomers plus the ${ }^{13} \mathrm{C}$ isotopologue of $m / z=78$ ) are attributed to the products of vinyl HACA reactions. The time-resolved signal intensities and the main reaction pathways for vinyl $+\mathrm{C}_{2} \mathrm{H}_{2}$ are available in the ESI. $\dagger$ This reaction network is under thorough study in our group, and will be discussed in detail in a separate publication. $\mathrm{H}$ atom consumption to form a vinyl radical is significant and is included in the model, but under our conditions further reactions of vinyl have negligible effects on the main peaks of interest here $(\mathrm{m} / \mathrm{z}=77,102,103,104,128,129)$. Other peaks observed in the MBMS experiments are attributed to the calibration mixture and hydrocarbon impurities in $\mathrm{C}_{2} \mathrm{H}_{2}$ or $\mathrm{C}_{6} \mathrm{H}_{5} \mathrm{NO}$, and show no discernible time dependence.

The conditions for each experiment are summarized in Table 1. In experiments 1-4, the concentration of $\mathrm{C}_{2} \mathrm{H}_{2}$ was controlled to achieve a rise time of $\sim 1.0 \mathrm{~ms}$ for the signal at $m / z=103$. Under these conditions, the signals corresponding to the main products-at $m / z=102,103,128$, and 129-appear within $2.0 \mathrm{~ms}$, and reach a steady state at $\sim 8.0 \mathrm{~ms}$. The reaction temperature $T$ was determined by averaging over temperature measurements at different points in the reactor, in this case averaged over the $5 \mathrm{~cm}$ length on the upstream side of the center pinhole, which corresponds to the MBMS sampling region during the time after the flash. The initial concentration of $\mathrm{C}_{6} \mathrm{H}_{5}$ after photolysis is the same as that of NO; therefore, the NO signal $(m / z=30)$ together with its known ionization cross section (3.1 $\mathrm{Mb}^{44}$ ) was used to determine the initial radical concentration. Time profiles of experimental measurements and the modeling results are shown in Fig. 4 for a short time scale $(2.0 \mathrm{~ms})$ and Fig. 5 for a long time scale $(8.0 \mathrm{~ms})$. The results for experiments 5-8 are given in the ESI, $\dagger$ and show that the product signals rise and reach a steady state earlier due to the faster reaction at higher $\mathrm{C}_{2} \mathrm{H}_{2}$ concentration.

Overall, the measurement and the model show quantitative agreement within the error bars for the experiments in Fig. 4 and 5. The model shows that phenylacetylene comprises almost $100 \%$ of the $m / z=102$ signal under all experimental conditions, as does naphthalene to the $m / z=128$ signal. At early time scales of up to $1.0 \mathrm{~ms}$, the signal at $\mathrm{m} / z=103$ increases rapidly due to the generation of initial adduct $\mathrm{C}_{8} \mathrm{H}_{7}-1$ by the $\mathrm{C}_{6} \mathrm{H}_{5}+\mathrm{C}_{2} \mathrm{H}_{2}(+\mathrm{M}) \rightarrow$ $\mathrm{C}_{8} \mathrm{H}_{7}-1(+\mathrm{M})$ reaction. The rise time for this species is faster than those for all other major products under our experimental conditions, except for the experiment at $700 \mathrm{~K}$ and 10 Torr. Under these relatively high temperature and low pressure conditions, the

Table 1 Conditions of MBMS experiments measuring the products of $\mathrm{C}_{6} \mathrm{H}_{5}+\mathrm{C}_{2} \mathrm{H}_{2}$

\begin{tabular}{|c|c|c|c|c|c|c|c|}
\hline Exp. \# & Nominal $T(\mathrm{~K})$ & Real $T(\mathrm{~K})$ & $P$ (Torr) & [Precursor] $^{a}\left(10^{13} \mathrm{~cm}^{-3}\right)$ & {$\left[\mathrm{C}_{6} \mathrm{H}_{5}\right]_{0}^{b, c}\left(10^{12} \mathrm{~cm}^{-3}\right)$} & {$\left[\mathrm{C}_{2} \mathrm{H}_{2}\right]^{a}\left(10^{16} \mathrm{~cm}^{-3}\right)$} & $k_{\text {sampling }}\left(\mathrm{s}^{-1}\right)$ \\
\hline 2 & 600 & $595.0 \pm 0.7$ & 50 & 2.1 & $0.93 \pm 0.19$ & 3.77 & 2000 \\
\hline 3 & 700 & $705.0 \pm 0.7$ & 10 & 2.2 & $0.92 \pm 0.18$ & 2.74 & 1600 \\
\hline 5 & 600 & $607.4 \pm 0.6$ & 10 & 2.2 & $1.05 \pm 0.21$ & 5.46 & 1800 \\
\hline 6 & 600 & $595.0 \pm 0.7$ & 50 & 2.1 & $0.99 \pm 0.20$ & 5.38 & 2000 \\
\hline 7 & 700 & $705.0 \pm 0.7$ & 10 & 2.2 & $0.80 \pm 0.16$ & 3.83 & 1200 \\
\hline
\end{tabular}

${ }^{a} 20 \%$ uncertainty due to mass flow controller calibrations. ${ }^{b}$ Calculated from a stable NO signal at $\mathrm{m} / \mathrm{z}=30$ after photolysis, $\sigma_{118 \mathrm{~nm}, \mathrm{NO}}=3.1 \mathrm{Mb} .{ }^{44}$

${ }^{c}$ Photolysis energy is $15 \mathrm{~mJ}$ per pulse. 
(a)

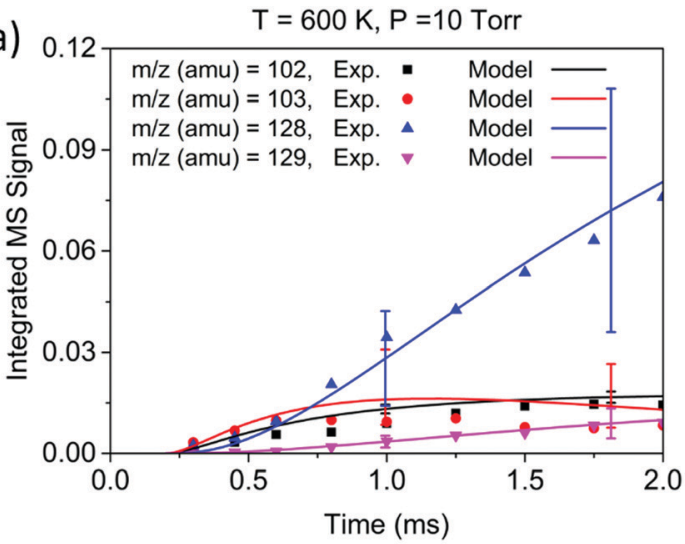

(c)

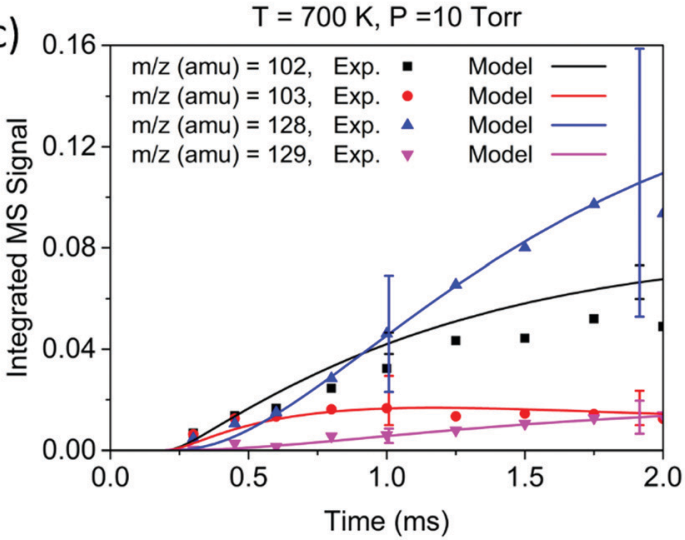

(b)

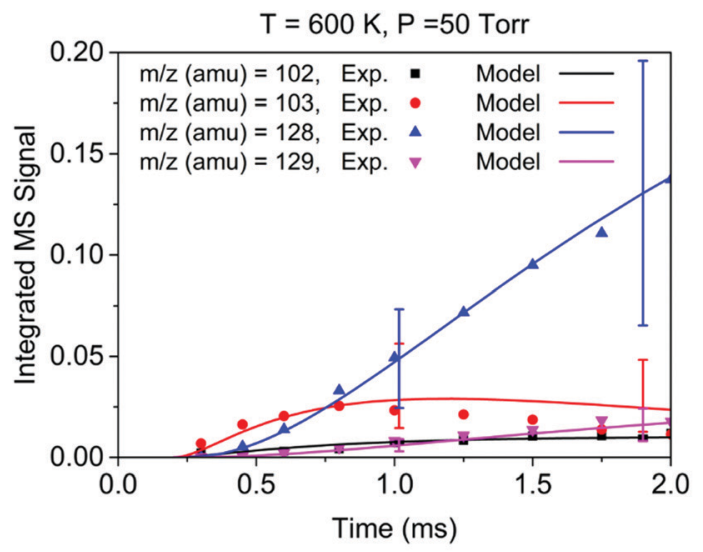

(d

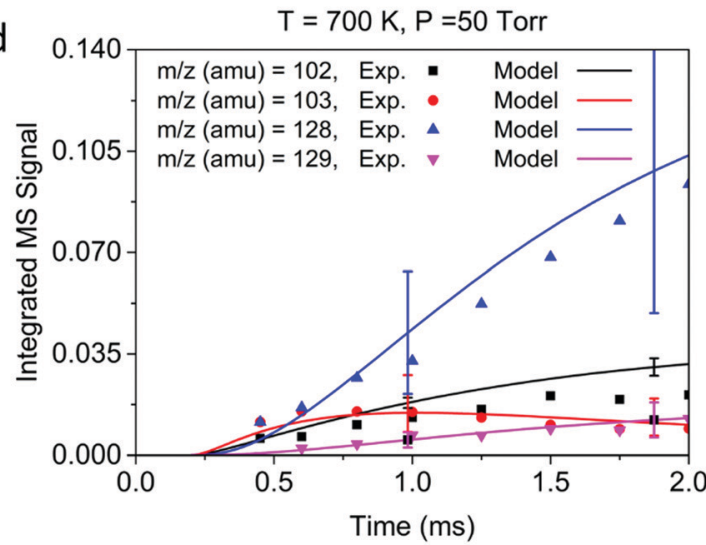

Fig. 4 Experimental time profiles (experiments 1-4, symbols) of primary product peaks measured by MBMS experiments at short time scales (2 ms). The solid curves are the model predictions. Uncertainty ranges of the model predictions (due to uncertainties in PICS) are shown as error bars. Conditions: (a) $600 \mathrm{~K}, 10$ Torr, $\left[\mathrm{C}_{2} \mathrm{H}_{4}\right]=3.82 \times 10^{16}$ molecule per cm ${ }^{3}$; (b) $600 \mathrm{~K}, 50$ Torr, $\left[\mathrm{C}_{2} \mathrm{H}_{4}\right]=3.77 \times 10^{16}$ molecule per $\mathrm{cm}^{3}$; (c) $700 \mathrm{~K}, 10 \mathrm{Torr}$, $\left[\mathrm{C}_{2} \mathrm{H}_{4}\right]=2.74 \times$ $10^{16}$ molecule per $\mathrm{cm}^{3}$; (d) $700 \mathrm{~K}, 50$ Torr, $\left[\mathrm{C}_{2} \mathrm{H}_{4}\right]=2.69 \times 10^{16}$ molecule per $\mathrm{cm}^{3}$.

"formally direct" pathway $\mathrm{C}_{6} \mathrm{H}_{5}+\mathrm{C}_{2} \mathrm{H}_{2}(+\mathrm{M}) \rightarrow$ phenylacetylene + $\mathrm{H}(+\mathrm{M})$ leads to a faster rate of phenylacetylene generation and thus a larger $m / z=102$ signal was observed in both the experiment and the model. We define "formally direct" pathways as reactions traversing more than one transition state; conversely, "mechanistically direct" pathways refer to reactions that have one transition state connecting reactants and products. ${ }^{56-59}$ At the beginning of the $\mathrm{C}_{6} \mathrm{H}_{5}+\mathrm{C}_{2} \mathrm{H}_{2}$ reaction, a rate-of-production (ROP) analysis indicates that $8.0 \%$ of $\mathrm{C}_{6} \mathrm{H}_{5}$ consumption directly forms $\mathrm{C}_{8} \mathrm{H}_{6}$ at $600 \mathrm{~K}$ and 10 Torr, compared to $16.3 \%$ at $700 \mathrm{~K}$ and 10 Torr. Furthermore, more $m / z=102$ signal was observed at higher temperature. At $700 \mathrm{~K}$, in addition to the "formally direct" pathway leading to $\mathrm{C}_{8} \mathrm{H}_{6}$ formation, thermalized $\mathrm{C}_{8} \mathrm{H}_{7}-1$ and $\mathrm{C}_{8} \mathrm{H}_{7}-2$ have more energy to overcome the barriers to $\mathrm{H}$ elimination, e.g. $\mathrm{C}_{8} \mathrm{H}_{7}-1(+\mathrm{M}) \rightarrow$ phenylacetylene $+\mathrm{H}(+\mathrm{M})$. As more $\mathrm{C}_{8} \mathrm{H}_{7}$ isomers react to form the $\mathrm{H}$-elimination product instead of reacting with a second $\mathrm{C}_{2} \mathrm{H}_{2}$ at higher temperatures, the relative yield of the phenylacetylene product at $\mathrm{m} / z=102$ is expected to increase over naphthalene at $m / z=128$. The ROP analysis shows that, at $1.0 \mathrm{~ms}$, the reaction channel $\mathrm{C}_{8} \mathrm{H}_{7}-1(+\mathrm{M}) \rightarrow \mathrm{C}_{8} \mathrm{H}_{6}+\mathrm{H}(+\mathrm{M})$ accounts for only $0.41 \%$ of $\mathrm{C}_{8} \mathrm{H}_{7}-1$ consumption at $600 \mathrm{~K}$ and 10 Torr, and it increases to $16.3 \%$ at $700 \mathrm{~K}$ and 10 Torr. The product distribution also exhibits a dependence on pressure in both the measurement and the model: at higher pressure, the formation of $\mathrm{C}_{8} \mathrm{H}_{7}$ adducts is favored over the bimolecular products $\mathrm{C}_{8} \mathrm{H}_{6}+\mathrm{H}$; therefore, the signal at $m / z=102$ becomes less significant when the pressure is increased from 10 to 50 Torr.

Unlike the $\mathrm{m} / z=102$ and $\mathrm{m} / z=128$ signals which are attributed to single species under our experimental conditions, the origin of the $\mathrm{m} / \mathrm{z}=103$ and $\mathrm{m} / \mathrm{z}=129$ signals is more complicated due to the combination of signals from multiple isomers as well as the contribution from ${ }^{13} \mathrm{C}$-substituted species. After reaching its maximum, the $\mathrm{m} / z=103$ signal is expected to decay to near zero because $\mathrm{C}_{8} \mathrm{H}_{7}-1$ and $\mathrm{C}_{8} \mathrm{H}_{7}-2$ are both highly reactive with $\mathrm{C}_{2} \mathrm{H}_{2}$. However, at $700 \mathrm{~K}$ after $3.0 \mathrm{~ms}$ in Fig. 5(c) and (d), the $m / z=103$ signal remains constant and above zero. According to the model, part of this signal comes from ${ }^{13} \mathrm{C}$-substituted phenylacetylene, which contributes $8 \times$ $1.1 \%$ of the $m / z=102$ signal to the signal at $m / z=103$. An interesting discovery is that the resonantly stabilized radical $\mathrm{C}_{8} \mathrm{H}_{7}-4$ has the highest concentration among all $\mathrm{C}_{8} \mathrm{H}_{7}$ isomers at later times, and accounts for $25 \%$ of the $\mathrm{m} / z=103$ signal at $700 \mathrm{~K}$ and 50 Torr at $8.0 \mathrm{~ms}$ in the model. Fig. 6 shows the modeled concentration of $\mathrm{C}_{8} \mathrm{H}_{7}$ isomers at $700 \mathrm{~K}$ and 50 Torr. The initial adduct $\mathrm{C}_{8} \mathrm{H}_{7}-1$ and its rapidly equilibrated isomer $\mathrm{C}_{8} \mathrm{H}_{7}-2$ both increase in concentration at early reaction times, 
(a)

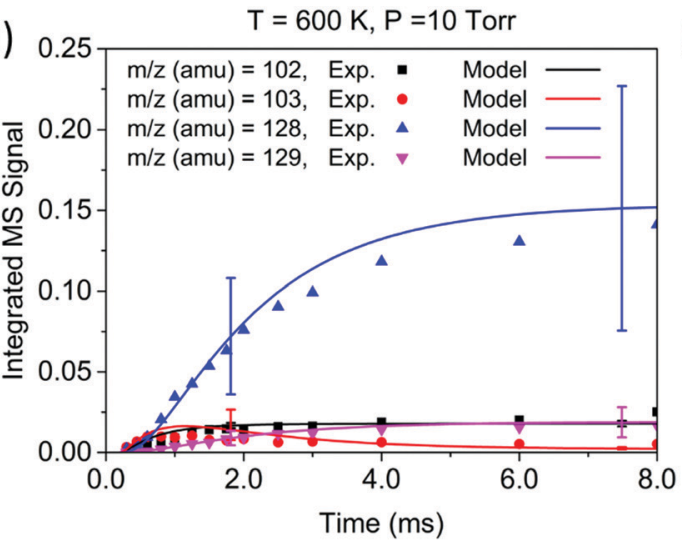

(c)

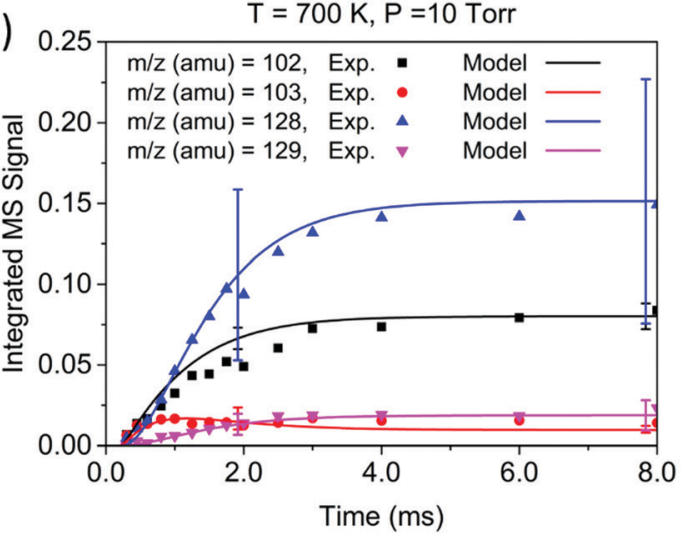

(b)

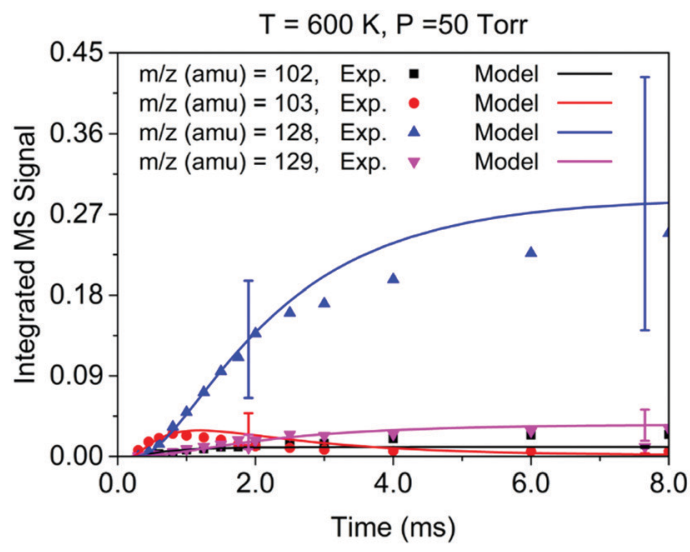

(d)

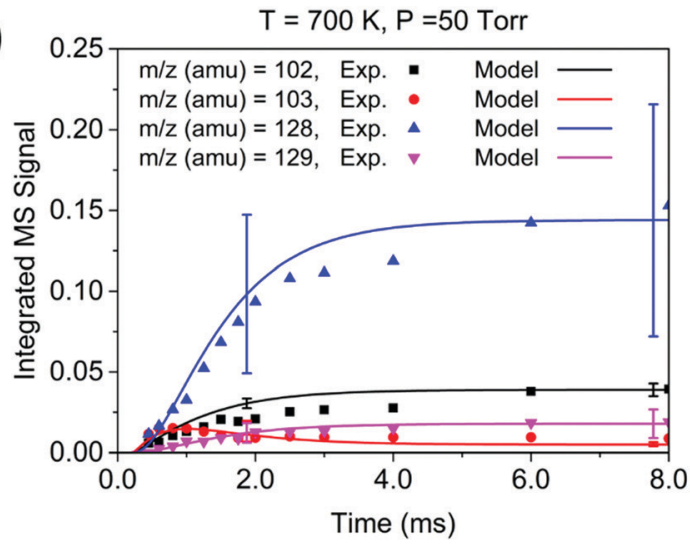

Fig. 5 Experimental time profiles (experiments 1-4, symbols) of primary product peaks measured by MBMS experiments at long time scales (8 ms). The solid curves are the model predictions. Uncertainty ranges of the model predictions are shown as error bars. Conditions: (a) $600 \mathrm{~K}, 10 \mathrm{Torr}$, $\left[\mathrm{C}_{2} \mathrm{H}_{4}\right]=$

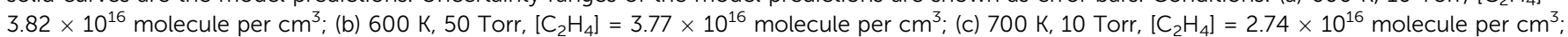
(d) $700 \mathrm{~K}, 50$ Torr, $\left[\mathrm{C}_{2} \mathrm{H}_{4}\right]=2.69 \times 10^{16}$ molecule per $\mathrm{cm}^{3}$.

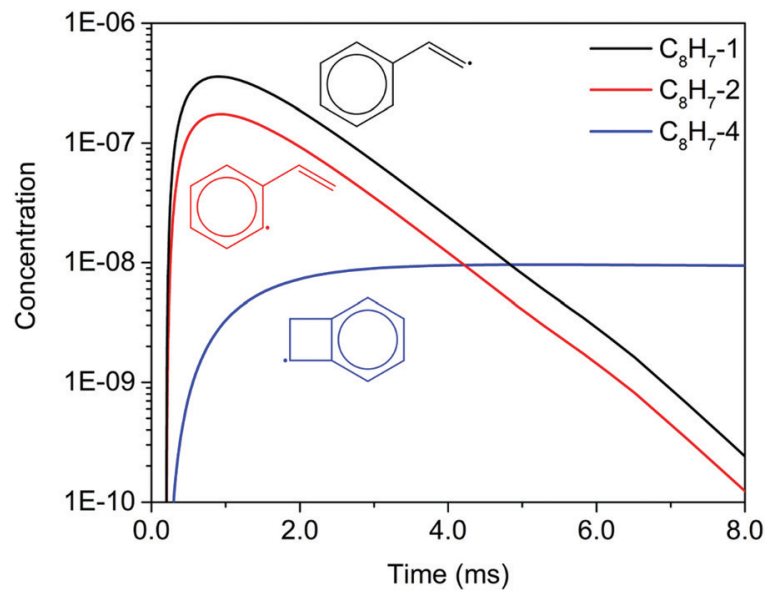

Fig. 6 Time dependent concentrations of $\mathrm{C}_{8} \mathrm{H}_{7}$ isomers predicted by the model at $700 \mathrm{~K}$ and 50 Torr.

but decrease significantly after $2.0 \mathrm{~ms}$. The concentration of $\mathrm{C}_{8} \mathrm{H}_{7}-4$ is negligible at early time scales, but exceeds the concentration of other isomers after $6.0 \mathrm{~ms}$. As seen in Fig. 1, $\mathrm{C}_{8} \mathrm{H}_{7}-4$ has the lowest energy of all species on the PES, and is surrounded by high barriers $\sim 40 \mathrm{kcal} \mathrm{mol}^{-1}$. After thermalized
$\mathrm{C}_{8} \mathrm{H}_{7}-2$ isomerizes into $\mathrm{C}_{8} \mathrm{H}_{7}-4$, the high energy barrier inhibits further reactions and thus leads to a long lifetime for the $\mathrm{C}_{8} \mathrm{H}_{7}-4$ radical. The signal at $m / z=129$ is attributed mainly to ${ }^{13} \mathrm{C}$-substituted naphthalene, and none of the $\mathrm{C}_{10} \mathrm{H}_{9}$ isomers included in the model are predicted to produce observable signals at any time scale under our experimental conditions. The model prediction implies that naphthalene is mainly formed by "formally direct" pathways: $\mathrm{C}_{8} \mathrm{H}_{7}-1+\mathrm{C}_{2} \mathrm{H}_{2}(+\mathrm{M}) \rightarrow$ naphthalene + $\mathrm{H}(+\mathrm{M})$ and $\mathrm{C}_{8} \mathrm{H}_{7}-2+\mathrm{C}_{2} \mathrm{H}_{2}(+\mathrm{M}) \rightarrow$ naphthalene $+\mathrm{H}(+\mathrm{M})$. According to the ROP analysis, $\mathrm{C}_{8} \mathrm{H}_{7}-1+\mathrm{C}_{2} \mathrm{H}_{2}(+\mathrm{M}) \rightarrow$ naphthalene $+\mathrm{H}(+\mathrm{M})$ accounts for $72.1 \%$ and $\mathrm{C}_{8} \mathrm{H}_{7}-2+\mathrm{C}_{2} \mathrm{H}_{2}(+\mathrm{M}) \rightarrow$ naphthalene $+\mathrm{H}(+\mathrm{M})$ accounts for $27.5 \%$ of naphthalene formation for the experiment at $700 \mathrm{~K}$ and 10 Torr at $1.0 \mathrm{~ms}$.

\subsection{Important reaction pathways and direct determination of branching ratios}

We have shown that the kinetic model developed in this work, containing reactions on the $\mathrm{C}_{8} \mathrm{H}_{7}, \mathrm{C}_{10} \mathrm{H}_{7}$, and $\mathrm{C}_{10} \mathrm{H}_{9}$ PESs calculated by Mebel et al. in addition to other important HACA reactions, is well validated by the MBMS experiments. Using the validated model, the most important reaction pathways can be identified under our experimental conditions $(600-700 \mathrm{~K}$, 10-50 Torr). As shown in Fig. 7, $\mathrm{C}_{6} \mathrm{H}_{5}$ reacts with $\mathrm{C}_{2} \mathrm{H}_{2}$ to form 


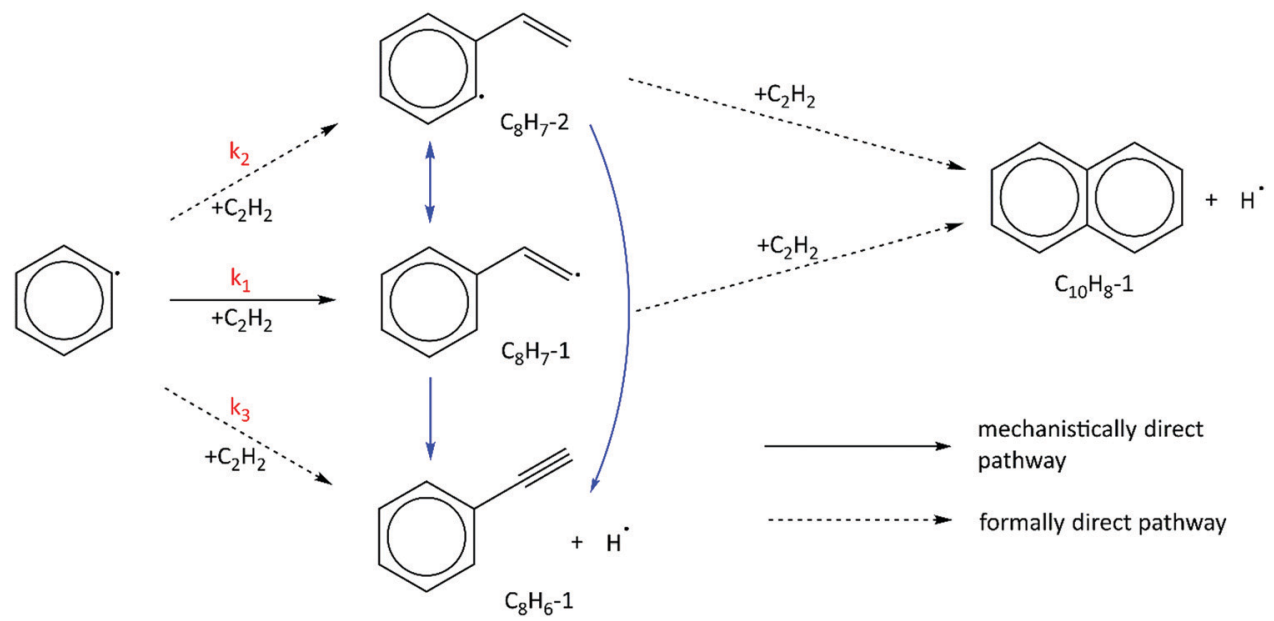

Fig. 7 Important reaction pathways identified by the validated phenyl $+\mathrm{C}_{2} \mathrm{H}_{2} \mathrm{HACA}$ model at 600-700 $\mathrm{K}$ and 10-50 Torr. Reaction pathways shown in blue can be ignored at high $\mathrm{C}_{2} \mathrm{H}_{2}$ concentration, where unimolecular reactions (reactions between $\mathrm{C}_{8} \mathrm{H}_{7}-1, \mathrm{C}_{8} \mathrm{H}_{7}-2$, and $\mathrm{C}_{8} \mathrm{H}_{6}-1+\mathrm{H}$ ) become negligible.

the initial adduct $\mathrm{C}_{8} \mathrm{H}_{7}-1$ via a mechanistically direct pathway, and generates $\mathrm{C}_{8} \mathrm{H}_{7}-2$ and the bimolecular products $\mathrm{C}_{8} \mathrm{H}_{6}-1+\mathrm{H}$ via formally direct pathways on the $\mathrm{C}_{8} \mathrm{H}_{7}$ PES. Isomerization between $\mathrm{C}_{8} \mathrm{H}_{7}-1$ and $\mathrm{C}_{8} \mathrm{H}_{7}-2$ appears to be significant in the model, as is the $\beta$-scission of both isomers into $\mathrm{C}_{8} \mathrm{H}_{6}-1+\mathrm{H}$. As discussed before, naphthalene $\left(\mathrm{C}_{10} \mathrm{H}_{8}-1\right)$ is formed mainly through formally direct pathways for the reactions of $\mathrm{C}_{8} \mathrm{H}_{7}-1$ and $\mathrm{C}_{8} \mathrm{H}_{7}-2$ with a second $\mathrm{C}_{2} \mathrm{H}_{2}$ molecule, without thermalizing the $\mathrm{C}_{10} \mathrm{H}_{9}$ isomers. The validated model shows that naphthalene dominates by at least three orders of magnitude over other $\mathrm{C}_{10} \mathrm{H}_{8}$ isomers; therefore, the present $\mathrm{m} / z=129$ signal observed in the MBMS experiments is fully attributed to the ${ }^{13} \mathrm{C}$ isotopologue of naphthalene. (Our model includes other $\mathrm{C}_{10} \mathrm{H}_{9}$ species $(m / z=129)$, but they have short lifetime, not persistent.)

At high $\mathrm{C}_{2} \mathrm{H}_{2}$ concentration, all the bimolecular reactions with $\mathrm{C}_{2} \mathrm{H}_{2}$ dominate over unimolecular reactions. The isomerization reactions between $\mathrm{C}_{8} \mathrm{H}_{7}-1$ and $\mathrm{C}_{8} \mathrm{H}_{7}-2$ and their $\beta$-scission into $\mathrm{C}_{8} \mathrm{H}_{6}-1+\mathrm{H}$ become negligible, such that only the bimolecular reactions including $\mathrm{C}_{6} \mathrm{H}_{5}+\mathrm{C}_{2} \mathrm{H}_{2}(+\mathrm{M}) \rightarrow \mathrm{C}_{8} \mathrm{H}_{7}-1(+\mathrm{M}), \mathrm{C}_{6} \mathrm{H}_{5}+$ $\mathrm{C}_{2} \mathrm{H}_{2}(+\mathrm{M}) \rightarrow \mathrm{C}_{8} \mathrm{H}_{7}-2(+\mathrm{M}), \mathrm{C}_{6} \mathrm{H}_{5}+\mathrm{C}_{2} \mathrm{H}_{2}(+\mathrm{M}) \rightarrow \mathrm{C}_{8} \mathrm{H}_{6}-1+\mathrm{H}$ $(+\mathrm{M}), \mathrm{C}_{8} \mathrm{H}_{7}-1+\mathrm{C}_{2} \mathrm{H}_{2}(+\mathrm{M}) \rightarrow \mathrm{C}_{10} \mathrm{H}_{8}-1+\mathrm{H}(+\mathrm{M})$, and $\mathrm{C}_{8} \mathrm{H}_{7}-2+$ $\mathrm{C}_{2} \mathrm{H}_{2}(+\mathrm{M}) \rightarrow \mathrm{C}_{10} \mathrm{H}_{8}-1+\mathrm{H}(+\mathrm{M})$ are significant. Since $\mathrm{C}_{10} \mathrm{H}_{8}-1+$ $\mathrm{H}$ are the sole final products for the bimolecular reactions of $\mathrm{C}_{8} \mathrm{H}_{7}-1$ and $\mathrm{C}_{8} \mathrm{H}_{7}-2$ with $\mathrm{C}_{2} \mathrm{H}_{2}$ and $\mathrm{C}_{10} \mathrm{H}_{8}-1$ fully dominates the $m / z=128$ signal, as is the case for $\mathrm{C}_{8} \mathrm{H}_{6}-1$ in the $m / z=102$ signal, we can use the signal ratio of $m / z=128$ and $\mathrm{m} / z=102$ to determine the product branching ratios of $\mathrm{C}_{6} \mathrm{H}_{5}+\mathrm{C}_{2} \mathrm{H}_{2}$ to $\mathrm{C}_{10} \mathrm{H}_{8}-1$ and $\mathrm{C}_{8} \mathrm{H}_{6}-1$ :

$$
\begin{aligned}
\frac{\text { Signal at } m / z 128}{\text { Signal at } m / z 102} & =\frac{C_{\text {naphthalene }} \times \sigma_{\text {naphthalene }} \times 0.90}{C_{\text {phenylacetylene }} \times \sigma_{\text {phenylacetylene }} \times 0.92} \\
& =\frac{\left(k_{1}+k_{2}\right) \times \sigma_{\text {naphthalene }} \times 0.90}{k_{3} \times \sigma_{\text {phenylacetylene }} \times 0.92}
\end{aligned}
$$

Branching fraction for adduct formation $=\frac{k_{1}+k_{2}}{k_{1}+k_{2}+k_{3}}$
Branching fraction for $\mathrm{H}$ loss

$$
\begin{aligned}
& =\frac{k_{3}}{k_{1}+k_{2}+k_{3}} \\
& =\frac{\frac{\text { Signal at } m / z 102}{\sigma_{\text {phenylacetylene }}} \times 0.92}{\frac{\text { Signal at } m / z 128}{\sigma_{\text {naphthalene }}} \times 0.90+\frac{\text { Signal at } m / z 102}{\sigma_{\text {phenylacetylene }}} \times 0.92}
\end{aligned}
$$

The $0.90 / 0.92$ factor in eqn (3) accounts for the ${ }^{13} \mathrm{C}$ isotope abundance; $k_{1}$ is the rate coefficient for $\mathrm{C}_{6} \mathrm{H}_{5}+\mathrm{C}_{2} \mathrm{H}_{2}(+\mathrm{M}) \rightarrow$ $\mathrm{C}_{8} \mathrm{H}_{7}-1(+\mathrm{M}) ; k_{2}$ is the rate coefficient for $\mathrm{C}_{6} \mathrm{H}_{5}+\mathrm{C}_{2} \mathrm{H}_{2}(+\mathrm{M}) \rightarrow$ $\mathrm{C}_{8} \mathrm{H}_{7}-2(+\mathrm{M})$; and $k_{3}$ is the rate coefficient for $\mathrm{C}_{6} \mathrm{H}_{5}+\mathrm{C}_{2} \mathrm{H}_{2}$ $(+\mathrm{M}) \rightarrow \mathrm{C}_{8} \mathrm{H}_{6}-1+\mathrm{H}(+\mathrm{M})$.

Experiments to evaluate product branching ratios were conducted under similar conditions to those of the MBMS experiments discussed in the previous section, but using much higher $\mathrm{C}_{2} \mathrm{H}_{2}$ concentrations. To avoid the molecular sampling effect on MBMS signals at early time scales, all the signal ratios were obtained at least $1.0 \mathrm{~ms}$ after photolysis. At least six different delay times were measured for each set of experimental conditions, and the ratio of $m / z=128$ to $m / z=102$ was observed to remain stable within the measured time range, as seen in Fig. 8. As this ratio increases, the yield of H-loss products decreases in favor of radical adduct stabilization (followed by reaction with $\mathrm{C}_{2} \mathrm{H}_{2}$ to form naphthalene). Uncertainty propagation was performed to estimate the uncertainty of H-loss branching measured in the experiments. The main source of uncertainty is the uncertainty in PICS of phenylacetylene and naphthalene; further details for the uncertainty analysis are included in the ESI. $\dagger$ Table 2 summarizes the experimental conditions and the H-loss branching measured by the MBMS experiments and predicted by the model developed in this work.

The product branching predicted by the model falls within the uncertainty of the measurements under all the conditions studied in this work. At $600 \mathrm{~K}$ and 10 Torr, 7.9\% of $\mathrm{C}_{6} \mathrm{H}_{5}$ reacts directly with $\mathrm{C}_{2} \mathrm{H}_{2}$ to form $\mathrm{C}_{8} \mathrm{H}_{6}-1+\mathrm{H}$, but this branching 


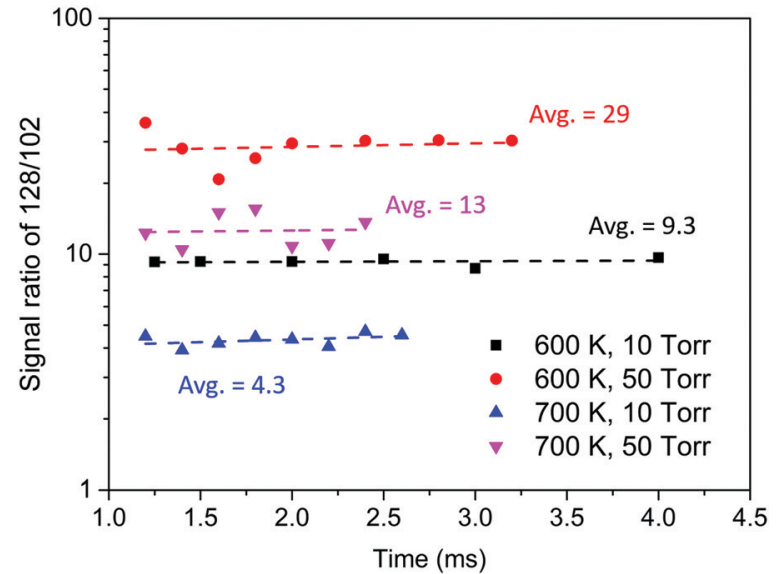

Fig. 8 Signal ratio of $\mathrm{m} / \mathrm{z}=128$ to $\mathrm{m} / \mathrm{z}=102$ measured in the MBMS experiments with high $\mathrm{C}_{2} \mathrm{H}_{2}$ concentration.

fraction decreases to $2.8 \%$ when the pressure is increased to 50 Torr. The reaction of $\mathrm{C}_{6} \mathrm{H}_{5}+\mathrm{C}_{2} \mathrm{H}_{2}$ can also form chemically activated $\mathrm{C}_{8} \mathrm{H}_{7}-1$, the fate of which depends on the competition between collisional stabilization $\left(k_{1}\right)$, isomerization followed by stabilization $\left(k_{2}\right)$, and $\beta$-scission $\left(k_{3}\right)$ under various temperature and pressure conditions. When the pressure increases, the greater efficiency of collisional stabilization of $\mathrm{C}_{8} \mathrm{H}_{7}-1$ by the bath gas reduces the probability of the formally direct $\mathrm{H}$-loss pathway to form $\mathrm{C}_{8} \mathrm{H}_{6}-1+\mathrm{H}$, since $\mathrm{C}_{8} \mathrm{H}_{7}-1$ is more likely to become stabilized before other reactions can occur. Therefore, higher pressure leads to a lower branching fraction for the $\mathrm{H}$-loss pathway, as was observed in the experiments at $700 \mathrm{~K}$ when the pressure was increased from 10 to 50 Torr (experiments 3 and 4). When the temperature is increased with pressure held constant, the $\mathrm{H}$-loss branching fraction increases by a factor of two from $7.9 \%(600 \mathrm{~K})$ to $15.9 \%(700 \mathrm{~K})$ at $10 \mathrm{Torr}$, and from $2.8 \%(600 \mathrm{~K})$ to $6.2 \%(700 \mathrm{~K})$ at 50 Torr. Higher temperatures lead to a greater probability that chemically activated $\mathrm{C}_{8} \mathrm{H}_{7}-1$ formed from the reaction of $\mathrm{C}_{6} \mathrm{H}_{5}$ with $\mathrm{C}_{2} \mathrm{H}_{2}$ has sufficient internal energy to overcome the barrier to undergo $\beta$-scission. Given the excellent agreement between the model and experiment for the time-dependent signals of main products and the direct $\mathrm{H}$-loss branching fractions, we conclude that our model has been thoroughly validated under the range of $T$ and $P$ conditions considered in this work. For future development of PAH formation mechanisms, the updated model derived from Mebel et al. ${ }^{14}$ presented here is therefore recommended to describe the HACA reactions of the phenyl radical with $\mathrm{C}_{2} \mathrm{H}_{2}$ as well as the formation of naphthalene.

\section{Conclusions}

$\mathrm{C}_{6} \mathrm{H}_{5}+\mathrm{C}_{2} \mathrm{H}_{2}$ HACA reaction pathways were studied experimentally with MBMS under a range of $T$ and $P$ conditions $(600-700 \mathrm{~K}$, 10-50 Torr) and with a pressure-dependent kinetic model built using Mebel's ab initio calculations on the $\mathrm{C}_{8} \mathrm{H}_{7}, \mathrm{C}_{10} \mathrm{H}_{7}$, and $\mathrm{C}_{10} \mathrm{H}_{9}$ PESs in addition to newly calculated pathways on the $\mathrm{C}_{8} \mathrm{H}_{7}$ PES at the G3(MP2,CC)//B3LYP/6-311G** level of theory and other important side reactions. Time-dependent signals at various mass-to-charge ratios $(\mathrm{m} / \mathrm{z})$ were measured, and the corresponding species concentrations predicted by the model were converted into expected signals for direct comparison with the MBMS experiments.

Under the conditions in this work, major product peaks at $m / z=102$ (H-loss product on the $\mathrm{C}_{8} \mathrm{H}_{7}$ PES, phenylacetylene), 103 (the initial adduct $\mathrm{C}_{8} \mathrm{H}_{7}-1$ and its isomers plus the ${ }^{13} \mathrm{C}$ isotopologue of phenylacetylene), 128 (naphthalene), and 129 $\left(\mathrm{C}_{10} \mathrm{H}_{9}\right.$ isomers plus the ${ }^{13} \mathrm{C}$ isotopologue of naphthalene) were observed. The modeled signals show excellent agreement with the measurements. As the temperature increases from 600 to $700 \mathrm{~K}$, the $m / z=102$ signal increases significantly relative to the $m / z=128$ signal, which indicates that product branching toward the H-loss pathway increases at higher temperature. When the pressure is increased from 10 to 50 Torr, more efficient collisional stabilization led to a higher rate of $\mathrm{C}_{8} \mathrm{H}_{7}$ adduct formation and a reduced yield of phenylacetylene. At long time scales (up to $8 \mathrm{~ms}$ after photolysis) at $700 \mathrm{~K}, \mathrm{C}_{8} \mathrm{H}_{7}$ radicals were expected to be completely consumed by bimolecular reactions due to the excess $\mathrm{C}_{2} \mathrm{H}_{2}$ concentrations in the reactor. However, the signal at $m / z=103$ corresponding to $\mathrm{C}_{8} \mathrm{H}_{7}$ remained constant and nonzero after $4.0 \mathrm{~ms}$. The model revealed that part of this signal came from ${ }^{13} \mathrm{C}$-substituted phenylacetylene, but more importantly, part of the signal was also attributed to a resonantly stabilized aromatic radical $\mathrm{C}_{8} \mathrm{H}_{7}-4$ which was newly calculated in this work.

At high $\mathrm{C}_{2} \mathrm{H}_{2}$ concentrations, $\mathrm{C}_{2} \mathrm{H}_{2}$ addition reactions become dominant. By measuring the signal ratio of $m / z=128$ to $\mathrm{m} / z=102$, the relative product branching of the formally direct $\mathrm{H}$-loss reaction pathway forming phenylacetylene on the $\mathrm{C}_{8} \mathrm{H}_{7}$ PES was directly determined. The measured phenylacetylene branching fractions are $7.9 \%$ at $600 \mathrm{~K}$ and 10 Torr, $2.8 \%$ at $600 \mathrm{~K}$ and 50 Torr, $15.9 \%$ at $700 \mathrm{~K}$ and 10 Torr, and $6.2 \%$ at $700 \mathrm{~K}$ and 50 Torr;

Table 2 Experimental conditions and results of $\mathrm{C}_{6} \mathrm{H}_{5}+\mathrm{C}_{2} \mathrm{H}_{2}$ product branching measurements

\begin{tabular}{|c|c|c|c|c|c|c|c|}
\hline Nominal $T(\mathrm{~K})$ & Real $T(\mathrm{~K})$ & $P$ (Torr) & $k^{\prime a}\left(10^{4} \mathrm{~s}^{-1}\right)$ & $\begin{array}{l}\text { Time } \\
\text { range (ms) }\end{array}$ & $\begin{array}{l}\text { Number of } \\
\text { time points }\end{array}$ & $\begin{array}{l}\text { Predicted H-loss } \\
\text { branching (\%) }\end{array}$ & $\begin{array}{l}\text { Measured H-loss } \\
\text { branching (\%) }\end{array}$ \\
\hline 600 & $607.4 \pm 0.6$ & 10 & 1.3 & $1.2-4.0$ & 6 & 8.0 & $7.9 \pm 4.9$ \\
\hline 600 & $595.0 \pm 0.7$ & 50 & 2.4 & $1.2-3.2$ & 8 & 2.6 & $2.8 \pm 1.6$ \\
\hline 700 & $705.0 \pm 0.7$ & 10 & 2.2 & $1.2-2.6$ & 8 & 16.4 & $15.9 \pm 8.0$ \\
\hline 700 & $693.1 \pm 1.0$ & 50 & 6.4 & $1.2-2.4$ & 7 & 6.3 & $6.2 \pm 3.4$ \\
\hline
\end{tabular}

${ }^{a} k^{\prime}=k \times\left[\mathrm{C}_{2} \mathrm{H}_{2}\right]$, where $k$ is the total rate constant of $\mathrm{C}_{6} \mathrm{H}_{5}+\mathrm{C}_{2} \mathrm{H}_{2}$ calculated by Mebel et al. ${ }^{14}$ 
the corresponding branching fractions predicted by the model agreed with the measurements within the experimental uncertainty under all the $T$ and $P$ conditions studied. The time-dependent products and product branching measured with MBMS successfully validate the kinetic model constructed in this work, and the rate parameters are recommended for future modeling of the phenyl + $\mathrm{C}_{2} \mathrm{H}_{2}$ HACA reaction in mechanisms of $\mathrm{PAH}$ formation.

\section{Conflicts of interest}

There are no conflicts to declare.

\section{Acknowledgements}

We gratefully acknowledge SABIC for financial support for this research, and Prof. Alexander Mebel for valuable discussions.

\section{References}

1 H. Richter and J. B. Howard, Prog. Energy Combust. Sci., 2000, 26, 565-608.

2 M. R. Kholghy, A. Veshkini and M. J. Thomson, Carbon, 2016, 100, 508-536.

3 M. Frenklach and H. Wang, Symp. (Int.) Combust., 1991, 23, 1559-1566.

4 M. Frenklach, Combust. Flame, 2019, 201, 148-159.

5 A. M. Valencia-López, F. Bustamante, A. Loukou, B. Stelzner, D. Trimis, M. Frenklach and N. A. Slavinskaya, Combust. Flame, 2019, 207, 265-280.

6 T.-C. Chu, Z. J. Buras, P. Oßwald, M. Liu, M. J. Goldman and W. H. Green, Phys. Chem. Chem. Phys., 2019, 21, 813-832.

7 V. Chernov, M. J. Thomson, S. B. Dworkin, N. A. Slavinskaya and U. Riedel, Combust. Flame, 2014, 161, 592-601.

8 K. Narayanaswamy, G. Blanquart and H. Pitsch, Combust. Flame, 2010, 157, 1879-1898.

9 M. Frenklach, D. W. Clary, W. C. Gardiner and S. E. Stein, Symp. (Int.) Combust., 1985, 20, 887-901.

10 H. Richter, O. A. Mazyar, R. Sumathi, W. H. Green, J. B. Howard and J. W. Bozzelli, J. Phys. Chem. A, 2001, 105, 1561-1573.

11 I. V. Tokmakov and M. C. Lin, J. Am. Chem. Soc., 2003, 125, 11397-11408.

12 V. V. Kislov, N. I. Islamova, A. M. Kolker, S. H. Lin and A. M. Mebel, J. Chem. Theory Comput., 2005, 1, 908-924.

13 Y. Georgievskii and S. J. Klippenstein, J. Phys. Chem. A, 2003, 107, 9776-9781.

14 A. M. Mebel, Y. Georgievskii, A. W. Jasper and S. J. Klippenstein, Proc. Combust. Inst., 2017, 36, 919-926.

15 A. Fahr and S. E. Stein, Symp. (Int.) Combust., 1989, 22, 1023-1029.

16 T. Yu, M. C. Lin and C. F. Melius, Int. J. Chem. Kinet., 1994, 26, 1095-1104.

17 T. Yu and M. C. Lin, J. Am. Chem. Soc., 1993, 115, 4371-4372.

18 D. S. N. Parker, R. I. Kaiser, T. P. Troy and M. Ahmed, Angew. Chem., Int. Ed., 2014, 53, 7740-7744.
19 T. Yang, T. P. Troy, B. Xu, O. Kostko, M. Ahmed, A. M. Mebel and R. I. Kaiser, Angew. Chem., Int. Ed., 2016, 55, 14983-14987.

20 J. E. Middaugh, Z. J. Buras, M. Matrat, T.-C. Chu, Y.-S. Kim, I. M. Alecu, A. K. Vasiliou, C. F. Goldsmith and W. H. Green, Rev. Sci. Instrum., 2018, 89, 074102.

21 Z. J. Buras, T. C. Chu, A. Jamal, N. W. Yee, J. E. Middaugh and W. H. Green, Phys. Chem. Chem. Phys., 2018, 20, 13191-13214.

22 J. E. Middaugh, PhD thesis, Massachusetts Institute of Technology, 2014.

23 M. J. Frisch, G. W. Trucks, H. B. Schlegel, G. E. Scuseria, M. A. Robb, J. R. Cheeseman, G. Scalmani, V. Barone, G. A. Petersson, H. Nakatsuji, X. Li, M. Caricato, A. V. Marenich, J. Bloino, B. G. Janesko, R. Gomperts, B. Mennucci, H. P. Hratchian, J. V. Ortiz, A. F. Izmaylov, J. L. Sonnenberg, D. Williams-Young, F. Ding, F. Lipparini, F. Egidi, J. Goings, B. Peng, A. Petrone, T. Henderson, D. Ranasinghe, V. G. Zakrzewski, J. Gao, N. Rega, G. Zheng, W. Liang, M. Hada, M. Ehara, K. Toyota, R. Fukuda, J. Hasegawa, M. Ishida, T. Nakajima, Y. Honda, O. Kitao, H. Nakai, T. Vreven, K. Throssell, J. A. Montgomery Jr., J. E. Peralta, F. Ogliaro, M. J. Bearpark, J. J. Heyd, E. N. Brothers, K. N. Kudin, V. N. Staroverov, T. A. Keith, R. Kobayashi, J. Normand, K. Raghavachari, A. P. Rendell, J. C. Burant, S. S. Iyengar, J. Tomasi, M. Cossi, J. M. Millam, M. Klene, C. Adamo, R. Cammi, J. W. Ochterski, R. L. Martin, K. Morokuma, O. Farkas, J. B. Foresman and D. J. Fox, Gaussian 16 Rev. B.01, Gaussian Inc., Wallingford, CT, 2016.

24 H. J. Werner, P. J. Knowles, G. Knizia, F. R. Manby and M. Schütz, WIREs Comput. Mol. Sci., 2012, 2, 242-253.

25 P. J. Knowles, C. Hampel and H. J. Werner, J. Chem. Phys., 1993, 99, 5219-5227.

26 P. J. Knowles and H. J. Werner, Theor. Chim. Acta, 1992, 84, 95-103.

27 P. J. Knowles, J. S. Andrews, R. D. Amos, N. C. Handy and J. A. Pople, Chem. Phys. Lett., 1991, 186, 130-136.

28 R. D. Amos, J. S. Andrews, N. C. Handy and P. J. Knowles, Chem. Phys. Lett., 1991, 185, 256-264.

29 P. J. Knowles and N. C. Handy, Comput. Phys. Commun., 1989, 54, 75-83.

30 H. J. Werner and P. J. Knowles, J. Chem. Phys., 1988, 89, 5803-5814.

31 P. J. Knowles and H. J. Werner, Chem. Phys. Lett., 1988, 145, 514-522.

32 H. J. Werner and P. J. Knowles, J. Chem. Phys., 1985, 82, 5053. 33 P. J. Knowles and H. J. Werner, Chem. Phys. Lett., 1985, 115, 259-267.

34 P. J. Knowles and N. C. Handy, Chem. Phys. Lett., 1984, 111, 315-321.

35 J. W. Allen, C. F. Goldsmith and W. H. Green, Phys. Chem. Chem. Phys., 2012, 14, 1131-1155.

36 C. W. Gao, J. W. Allen, W. H. Green and R. H. West, Comput. Phys. Commun., 2016, 203, 212-225.

37 A. M. Mebel, Y. Georgievskii, A. W. Jasper and S. J. Klippenstein, Faraday Discuss., 2016, 195, 637-670.

38 A. W. Jasper, C. M. Oana and J. A. Miller, Proc. Combust. Inst., 2015, 35, 197-204. 
39 Y. Georgievskii and S. J. Klippenstein, MESS.2016.3.23.2016.

40 Y. Georgievskii, J. A. Miller, M. P. Burke and S. J. Klippenstein, J. Phys. Chem. A, 2013, 117, 12146-12154.

41 H. Wang and M. Frenklach, Combust. Flame, 1994, 96, 163-170.

42 K. Han, A. Jamal, C. A. Grambow, Z. J. Buras and W. H. Green, Int. J. Chem. Kinet., 2018, 50, 294-303.

43 M. T. Baeza-Romero, M. A. Blitz, A. Goddard and P. W. Seakins, Int. J. Chem. Kinet., 2012, 44, 532-545.

44 T. Adam and R. Zimmermann, Anal. Bioanal. Chem., 2007, 389, 1941-1951.

45 Z. Zhou, M. Xie, Z. Wang and F. Qi, Rapid Commun. Mass Spectrom., 2009, 23, 3994-4002.

46 Y. Y. Li, J. Z. Yang and Z. J. Cheng, Photonionization Cross Section Database (Version2.0), http://flame.nsrl.ustc.edu. cn/database/.

47 Y. Li, L. Zhang, Z. Tian, T. Yuan, J. Wang, B. Yang and F. Qi, Energy Fuels, 2009, 23, 1473-1485.

48 H. Xu and S. T. Pratt, J. Phys. Chem. A, 2013, 117, 9331-9342. 49 Y. A. Dyakov, J. Chem. Phys., 2012, 137, 064314.
50 Chemical Workbench 4.1.18493, Kintech Lab, Moscow, Russia, 2016.

51 H. Wang and M. Frenklach, J. Phys. Chem., 1994, 98, 11465-11489.

52 J. D. Bittner and J. B. Howard, Symp. (Int.) Combust., 1981, 18, 1105-1116.

53 N. W. Moriarty, N. J. Brown and M. Frenklach, J. Phys. Chem. A, 1999, 103, 7127-7135.

54 M. Frenklach, N. W. Moriarty and N. J. Brown, Symp. (Int.) Combust., 1998, 27, 1655-1661.

55 B. M. Wong, D. M. Matheu and W. H. Green, J. Phys. Chem. A, 2003, 107, 6206-6211.

56 J. Zádor, C. A. Taatjes and R. X. Fernandes, Prog. Energy Combust. Sci., 2011, 37, 371-421.

57 A. M. Knepp, G. Meloni, L. E. Jusinski, C. A. Taatjes, C. Cavallotti and S. J. Klippenstein, Phys. Chem. Chem. Phys., 2007, 9, 4315-4331.

58 E. G. Estupiñán, J. D. Smith, A. Tezaki, S. J. Klippenstein and C. A. Taatjes, J. Phys. Chem. A, 2007, 111, 4015-4030.

59 J. D. DeSain, S. J. Klippenstein, J. A. Miller and C. A. Taatjes, J. Phys. Chem. A, 2003, 107, 4415-4427. 